\title{
ESTUDO SOBRE A TEXTUALIZAÇÃO: Entre a produção discente $e$ a intervenção docente
}

\author{
STUDIES ON TEXTUALIZATION: \\ Between students production and teachers intervention
}

\begin{abstract}
Aline Cassol Daga
Mestranda em Linguística - Universidade Federal de Santa Catarina

Artur de Vargas Giorgi

Mestrando em Literatura - Universidade Federal de Santa Catarina

Letícia Laurindo de Bonfim

Universidade Federal de Santa Catarina
\end{abstract}

\begin{abstract}
Resumo
Este breve artigo tem por objetivo levantar algumas questões acerca das intervenções docentes na textualização dos alunos. Assim, analisamos as intervenções feitas por duas professoras de Português nas redações de quatro alunos, à luz das teorias de Grice (1975), Charolles (1978), Beaugrande e Dressler (1981) e Halliday e Hasan (1976). O escopo dessas análises foi a tentativa de identificar, pontualmente, as possíveis bases teóricas que pautaram as correções feitas pelas docentes. Posteriormente, consideramos o observado, refletindo quanto ao que poderia ser otimizado na interação entre a produção textual dos discentes e a correção das professoras, a fim de que tais correções fossem mais produtivas e enriquecedoras.
\end{abstract}

Palavras-chave: Texto. Textualização. Coesão. Coerência. Intervenção docente.

\begin{abstract}
This article aims to analyse the feedback of two Portuguese teachers in four students' essays. The analysis was based on the studies developed by Grice (1975), Charolles (1978), Beaugrande and Dressler (1981), and Halliday and Hasan (1976), which enabled the researcher to identify the possible theoretical bases that have supported the feedback carried out by the school teachers. Suggestions are made regarding what could be optimized in the interaction between the students' texts and their teachers' feedback so as to enhance the students' text production.
\end{abstract}

Keywords: Text. Textualization. Cohesion. Coherence. Teachers’ intervention.

\section{INTRODUÇÃO}

No estudo do Português, tanto no Ensino Fundamental quanto no Ensino Médio, um dos momentos mais delicados e cruciais, para alunos e, também, para professores, é o que envolve a produção textual.

Para os alunos, coloca-se o desafio de superar as dificuldades ligadas ao manejo escrito do sistema linguístico, da norma gramatical postulada pelos livros didáticos e, acima de tudo, de, através desse mesmo sistema e dessa mesma norma, organizar coesa e coerentemente suas ideias, de modo a produzir um texto relevante do ponto de vista do que é proposto pelo professor. 
No ponto oposto - mas complementar - do processo de produção textual, professores assumem papel dúplice: são leitores e revisores (ou corretores) dos textos produzidos pelos alunos. A eles cabe a fundamental tarefa de ler, avaliar e intervir no texto, de modo que essas intervenções sejam elucidativas para os alunos, contribuindo para o aprimoramento de sua leitura, sua escrita e de sua proficiência no uso da língua de maneira geral.

Sobre a tarefa docente, muitas são as formas de "tocar" o texto do aluno. Em uma dessas possibilidades, as gramáticas tradicionais fornecem as bases teóricas para reparar erros de ortografia, acentuação, concordância, etc. - erros facilmente detectáveis, já que "visíveis" na superfície do texto por meio de regras (e exceções a regras) em grande medida objetivas. No entanto, para além do nível gramatical, professores não podem (ao menos não poderiam) negligenciar a forma como o texto deve ser apreendido em sua totalidade, possuidor de relações de coesão e coerência que precisam ser respeitadas.

São várias as teorias que se detêm sobre a questão da coesão e da coerência textuais. Para este artigo, são consideradas fundamentais as ideias de Grice (1975 apud SANTOS, 1997), Charolles (1978), Beaugrande e Dressler (1981 apud KOCH, 2004) e Halliday e Hasan (1976 apud KOCH, 1999). Logicamente, as apreciações sobre o que é coesão e o que é coerência variam, em certo grau, entre esses teóricos, todavia, à parte algumas peculiaridades, podemos, de modo geral, aproximá-los, já que consideram em seus estudos o mesmo problema: o que faz com que conjuntos de frases e seus significados, colocados em sequência, sejam considerados textos; e que orientações devem ser seguidas para que, no uso da língua escrita, os textos considerados apresentem aprimoradas as "qualidades" que, de maneira geral, se resumem aos índices de coesão e coerência.

\section{AS BASES TEÓRICAS}

Em Grice (1975 apud SANTOS, 1997), filósofo da linguagem vinculado à pragmática norte-americana, encontramos os chamados Princípios da Cooperação - Máximas Conversacionais (Quantidade, Qualidade, Relevância e Modo) e Implicaturas Conversacionais. Esses princípios, inicialmente ligados ao uso da linguagem oral, foram trazidos por Santos (1997) ao plano da linguagem escrita e, a partir deles, podemos considerar algumas estratégias (a observância das próprias Máximas) que fazem do texto (neste caso, as redações dos alunos) um "[...] local onde um autor e um leitor encontram-se, dialogam, interagem” (SANTOS, 1997, p. 42).

Charolles (1978), por sua vez, introduziu em sua obra algumas problematizações referentes à coerência dos textos, elaboradas a partir da intervenção de professores “[...] frente a certos textos escritos de alunos julgados por ele como incoerentes” (1997, p. 40). Em seu raciocínio, Charolles elaborou as chamadas Metarregras de Coerência (Continuidade, Progressão, Não-contradição, Relação), com as quais buscava fornecer critérios teóricos para uma abordagem da coerência textual e discursiva, a exemplo das abordagens praticadas tradicionalmente, sustentadas em bases normativas e gramaticais. 
Retomadas, no Brasil, por Koch (2004), as ideias de Beaugrande e Dressler (1981), apresentaram sete critérios que serviram como princípios de construção textual de sentido. Para os dois autores, os critérios dividiam-se entre aqueles que eram "centrados no texto" (coesão, coerência) e os que eram "centrados no usuário”, também chamados "fatores pragmáticos de textualidade" (situacionalidade, informatividade, intertextualidade, intencionalidade e aceitabilidade). A divisão sugerida, não-consensual entre as diferentes teorias utilizadas, foi criticada; contudo, importa que os estudos de Beaugrande e Dressler permaneceram como uma das teorias seminais da textualidade.

Finalmente, como última base teórica que tomaremos por referência no presente estudo, Halliday e Hasan (1976), também, no Brasil, a partir de Koch (1999), trouxeram em suas ideias os conceitos e mecanismos (Referência, Substituição, Elipse, Conjunção e Coesão Lexical) de coesão textual. Para eles, o conceito de coesão textual era "[...] um conceito semântico que se refere às relações de sentido existentes no interior do texto e que o definem como um texto" (KOCH, 1999, p. 17). Outros autores se contrapuseram a algumas de suas definições; mas as teorizações de Halliday e Hasan sobre as relações de sentido (por meio de recursos semânticos do sistema léxico-gramatical) na ligação entre as sentenças são ainda muito proveitosas para constituição do conhecimento de professores de língua portuguesa.

\section{METODOLOGIA}

Para este estudo, recolhemos quatro redações redigidas por, também, quatro alunos do primeiro ano do Ensino Médio, duas dessas produções textuais foram corrigidas por uma professora, a qual chamaremos Professora 1 e, os dois textos restantes, foram corrigidos por outra professora, a Professora 2. Realizamos conversas informais com as professoras, de maneira que pudessemos ter acesso aos textos (da turma de cada professora, dois textos - Anexos), e nos situarmos das propostas envolvidas no processo de escritura das redações. De acordo com o que nos disse a Professora 1, as redações haviam sido solicitadas após uma aula de Geografia, na qual os estudantes assistiram ao vídeo à respeito de Martin Lutero, esse vídeo sustentou a temática desenvolvida na dissertação. Já a Professora 2, propôs o “amor” como tema do texto, e o explorou previamente através de algumas frases que estão expostas na análise da Professora 2.

Com as redações em mãos, observamos, pontualmente, mas também em sua regularidade, as intervenções praticadas pelas professoras nas redações dos alunos, contrapondo-as em sua proximidade, ou seu distanciamento, em relação às teorias por nós apresentadas.Em nenhum momento, as teorias citadas foram comentadas com as professoras; muito menos as profissionais foram questionadas quanto ao seu conhecimento de teorias sobre o texto e a textualização.

De acordo com o objetivo do trabalho, concluiríamos pelo conhecimento ou não dessas teorias através da própria análise das correções; ou seja, pelo que pareceu pautar a avaliação feita pelas professoras enquanto elas liam e corrigiam os textos de seus alunos

\section{SOBRE AS PROFESSORAS}

Uma das professoras, a qual trataremos por Professora 1, tem 32 anos e leciona há seis anos. Formou-se no ano de 2000 em Letras - Língua Portuguesa e Língua Inglesa, pela 
Faculdade de Filosofia, Ciências e Letras de Palmas - Paraná (FAFI). Por possuir habilitação dupla, podendo atuar tanto na área de Português como na de Inglês, optou por dar aulas de Inglês na maior parte do tempo; somente após três anos ela voltou a lecionar Português.

Quando questionada sobre a formação que teve e se sentia segurança para dar aulas de português, ela respondeu que considera que a habilitação dupla forma precariamente os profissionais, tanto na área de Português como na de Inglês, pois os conteúdos estudados são superficiais; muitos conhecimentos não são explorados como deveriam, devido ao curto tempo da graduação em relação à abrangência do conteúdo.

No que diz respeito à formação para atuar como professora de Português e, mais especificamente, como profissional capacitada a intervir nos textos dos alunos, fazendoos indivíduos proficientes em escrita, a hipótese, segundo essa conversa informal, é de que a Professora 1 não recebeu o devido preparo para desempenhar com excelência essa função.

A outra professora, neste artigo chamada de Professora 2, tem 28 anos e concluiu o curso de Língua Portuguesa e Literatura da Língua Portuguesa em fevereiro de 2008, pela Universidade Comunitária Regional de Chapecó (UNOCHAPECÓ).

A exemplo da Professora 1, durante a conversa que tivemos, a Professora 2 disse não se sentir preparada para corrigir textos de alunos, pois ela mesma admitiu-se muito insegura na produção de seus próprios textos. Além da falta de preparação teórica, essa insegurança talvez possa ser explicada, em suas palavras, pelo fato de ela não gostar do curso que fez; a Professora 2 só concluiu o curso para ter um diploma e não pretendia seguir atuando na área docente.

\section{ANÁLISE E DISCUSSÃO DAS REDAÇÕES CORRIGIDAS PELA PROFESSORA 1}

Os textos corrigidos pela Professora 1 são de dois alunos da primeira série do Ensino Médio. As produções textuais solicitadas por ela, foram um meio de avaliar uma atividade realizada na aula de Geografia. A proposta era a de que os alunos produzissem uma dissertação sobre o vídeo de Martin Lutero, a que assistiram.

A correção das dissertações pautou-se na estrutura textual, dando menos atenção às questões gramaticais. À exemplo disso, tem-se a intervenção feita na redação 1 (Anexo 1): "Seu desenvolvimento ficou incompleto, bem como sua conclusão", percebendo-se, assim, que o comentário feito, diz respeito à estrutura textual; no entanto, a professora não marcou especificamente os problemas encontrados no desenvolvimento. E, com base neste apontamento e nos seguintes, pode-se levantar algumas questões.

O ponto que mais chama atenção nessa redação é a confusão entre a ordem dos acontecimentos do filme e a estrutura textual. Em alguns trechos, ao narrar o filme, o aluno dá muitas informações novas sem discorrer suficientemente sobre elas, tornando a redação confusa e, infringindo, assim, a Metarregra da Relação (CHAROLLES, 1978); quem assistiu ao filme, ou tem conhecimentos prévios a respeito da vida de Martin Lutero, consegue estabelecer uma relação entre as informações dispostas no texto, pois 
elas estão subentendidas, no entanto, para aqueles que não se incluem neste grupo, o texto parece uma junção de informações soltas. Isso é claramente perceptível nos cinco últimos parágrafos da redação, onde a professora interfere dizendo que o trecho está confuso, mas não aponta o motivo de tal confusão.

O texto não apresenta uma introdução adequada, infringindo, dessa forma, a situacionalidade, que, para Beaugrande e Dressler (1981), deve ser considerada quando nos referimos à coerência textual. Segundo esses autores, o texto deve estar adequado a uma determinada situação comunicativa, o que depende do grau de formalidade, regras de polidez, etc. Nesse caso, o aluno deveria iniciar e concluir o texto respeitando a estrutura dissertativa, introduzindo o assunto a ser tratado, mas, ao invés disso, o texto apresenta uma estrutura narrativa.

O início da redação e o seu desenrolar tratam de assuntos como o motivo pelo qual Lutero decide tornar-se monge; logo, o texto segue falando das discordâncias do personagem em relação ao pagamento de indulgências, até a escritura de suas 95 teses. Os assuntos tratados até este trecho apresentam progressão semântica (CHAROLLES, 1978), embora estejam divididos em cinco parágrafos e sejam tratados quase como tópicos dentro de um mesmo assunto. Neste parágrafo, a professora chamou atenção para a confusão, mas sua intervenção poderia apontar esse tipo de problema de forma mais específica e mostrar recursos gramaticais para resolvê-lo, como, por exemplo, o uso de conjunções, para estabelecer uma relação explicita entre as informações dispostas no texto.

A redação 2 (Anexo 2), assim como a primeira, segue uma estrutura predominantemente narrativa, infringindo, deste modo, a situacionalidade (BEAUGRANDE; DRESSLER, 1981). Através do enunciado da atividade proposta e dos apontamentos da professora, observa-se que ela esperava um texto dissertativo, por isso, mais uma vez, ela ressalta o fato de a redação iniciar sem introdução. Assim, a situacionalidade (BEAUGRANDE; DRESSLER, 1981, é desrespeitada novamente, primeiro, pela estrutura narrativa e, depois, por não apresentar uma introdução, a maneira mais adequada de começar o texto dissertativo. O primeiro parágrafo, embora infrinja a situacionalidade,como já foi esclarecido anteriormente, apresenta progressão semântica (CHAROLLES, 1978) e elementos de ligação entre um período e outro, o que faz com que o assunto se mantenha o mesmo apenas com o acréscimo de informações novas.

O segundo parágrafo, por sua vez, é mais problemático, pois narra os acontecimentos do filme dando muitas informações e não discorrendo sobre elas, ferindo assim, a informatividade (BEAUGRANDE; DRESSLER, 1981), e, acarretando na quebra de relação. No terceiro parágrafo, a aluna escreve que o Papa toma conhecimento das teses de Lutero, que é, então, excomungado pela Igreja católica, capturado, preso e decide traduzir a bíblia para o alemão. Percebe-se que a estrutura desse parágrafo, mais uma vez, é narrativa e não dissertativa. Para esse problema, a intervenção feita pela professora foi a de que a aluna deveria explicitar que a bíblia estava escrita em latim, por isso, Lutero tinha intenção de traduzi-la para o alemão. Dessa forma, poderíamos dizer que a professora, mesmo sem saber, interveio na Qualidade e na Quantidade de informações do texto, isto é, intuitivamente, ela empregou princípios das Máximas de Grice. 
O quarto parágrafo aborda a reforma religiosa, remetendo, assim, ao assunto tratado no início do texto, a discordância de Lutero com a Igreja Católica em função do pagamento de indulgências; porém não há qualquer elo entre a causa e a consequência desses fatos, pois entre esses dois assuntos há um terceiro, quebrando a possibilidade de relação entre os assuntos do texto. Esse parágrafo deveria passar a ser o segundo, assim haveria continuidade nos temas tratados: a discordância em relação à Igreja, a escritura das teses, a reforma, para depois tratar da captura de Lutero.

Os dois últimos parágrafos do texto misturam dados biográficos de Lutero com os confrontos apresentados no filme. Essa confusão de temas resulta, consequentemente, na quebra da relação (CHAROLLES, 1978). E, por fim, o trecho que deveria ser a conclusão da dissertação introduz um novo assunto; novamente, tem-se o problema de adequação do texto ao seu formato dissertativo, infringindo a situcionalidade (BEAUGRANDE; DRESSLER, 1981).

As intervenções da professora foram plausíveis. Ela apontou que o desenvolvimento poderia ser mais detalhado, o que remete ao problema de informatividade do texto, e ainda mencionou a falta da introdução, o que também procede; no entanto, detalhar os procedimentos para melhorar a estrutura da dissertação faz parte do papel do professor;assim, ela poderia pontuar cada problema e mostrar soluções precisas para a melhoria do texto.

\section{ANÁLISE E DISCUSSÃO DAS REDAÇÕES CORRIGIDAS PELA PROFESSORA 2}

Os textos corrigidos pela Professora 2 são, também, de dois alunos da primeira série do Ensino Médio. Essas produções textuais foram solicitadas após uma aula na qual o tema foi o amor, sendo que cada aluno recebeu uma folha com as seguintes instruções:

Leia algumas frases sobre o amor:

Amai-vos uns aos outros como eu vos amei (Jesus Cristo)

O amor é eterno enquanto dura (Henri Régnier)

$O$ amor deixa de ser um prazer quando deixa de ser um segredo (Aphra Behn)

O amor é a única paixão que não admite nem passado nem futuro (Balzac)

E para você, o que é o amor?

A correção dos textos, feita pela professora, foi superficial: além de ter feito apenas correções gramaticais, identificando erros de ortografia, por exemplo, muitas dessas intervenções foram feitas de maneira equivocada ("corrigindo" o que estava certo, ou sugerindo soluções também erradas do ponto de vista normativo) e outras, que deveriam ter sido apontadas, passaram despercebidas.

Na redação intitulada “O Amor” (Anexo 3), a professora fez correções gramaticais de forma indevida; logo na primeira linha do texto, ela colocou uma vírgula em um lugar não apropriado, como vemos a seguir, transcrevendo a redação: "O amor é uma única, paixão que não admite erro" (a vírgula, sugerida pela professora). Além disso, ela não corrigiu a grafia da palavra "apesar”, que o aluno escreveu "apessar”, entre outras correções não feitas ou equivocadas. 
Para o nível da compreensão geral do texto, a redação apresenta sérios problemas de coerência e coesão, os quais não foram apontados pela professora - o que é grave, pois a coerência é fator fundamental da textualidade, por ser responsável pelo sentido do texto. O primeiro problema que observamos encontra-se na linha inicial, onde há uma afirmação obscura ("O amor é uma única, paixão que não admite erro"), se considerarmos a relação entre amor e paixão,dois conceitos "porosos", de difícil determinação, e também em relação à noção de erro. Essa sentença precisaria ser reformulada para que se tornasse mais clara.

Além da não-existência de uma estrutura textual própria da dissertação (com um posicionamento sobre um tema proposto), com introdução, desenvolvimento e conclusão - o que não está comprometida com a situcionalidade estabelecida por Bergraunde e Dressler (1981) -, o que chama mais a atenção é a "lenga-lenga" produzida pelo aluno, como se ele não tivesse nada a dizer. O texto não apresenta progressão semântica, tornando-se totalmente circular, sendo que as únicas idéias que o atravessam são baseadas no senso comum: "devemos amar uns aos outros" e "o amor surge quando mais precisamos". Nesse sentido, poderíamos questionar se a redação do aluno não infringe a Máxima da Qualidade de Grice, já que as "verdades" proferidas pelo texto são relativas e devem ser colocadas em certo contexto para que possam ser defendidas criteriosamente. Além disso, no desenvolvimento, há uma tentativa de definição do amor por meio de uma estrutura que não se renova - o aluno repete a seqüência "o amor é”, ao invés de usar recursos coesivos interfrasais, como as referências exofóricas, endofóricas ou a elipse, propostas por Halliday e Hasan (1976), citadas por Koch (1999, p. 20-21); no caso, a repetição da mesma expressão, como vimos, não constitui uma "qualidade", nem favorece o entendimento; ao contrário, torna a leitura cansativa e pobre de recursos coesivos.

Outro fator que devemos destacar é o da intertextualidade, a partir de Bergraunde e Dressler (1981). No texto do aluno, percebemos, como já mencionado, o discurso anônimo do senso comum, além da retomada das idéias dos fragmentos dados pela professora na proposta da redação. No entanto, nesse texto, essa intertextualidade é negativa, pois são informações previsíveis que baixaram o grau de informatividade do texto, violando, assim, a máxima da Relevância.

Já a redação “O que é Amor?” (Anexo 4), ao contrário da primeira, tem progressão semântica, pois há o acréscimo de informações novas ao longo do texto. No entanto, muitas dessas informações novas não estabelecem relação entre si, o que, segundo a teoria de Charolles (1978), infringe a Metarregra da Relação. Isso pode ser percebido ao longo do texto, o qual muda de foco várias vezes, apesar de ser sempre uma tentativa de definição e qualificação do amor. No segundo parágrafo, por exemplo, há uma mudança brusca do foco; enquanto o primeiro parágrafo lista uma série de definições do amor, o segundo inicia “falando" das diferentes formas de expressá-lo.

Se tomarmos por base as Máximas estabelecidas por Grice, perceberemos outro problema no segundo parágrafo do texto. A sentença “[...] outros apenas amam; mas todos amam, não importando a raça nem a cor” infringe a Máxima da Qualidade e da Quantidade, pois é questionável a importância da raça e da cor de uma pessoa quando se fala em amor. Além disso, a quantidade de informações transmitidas é baixa, o que dificulta ainda mais o entendimento e a clareza do texto. 
Além dos problemas de textualização já apontados, há outros que poderiam ser discutidos com base nas teorias citadas, no entanto o importante foi constatar que os dois textos não foram construídos segundo o que essas teorias postulam sobre textualização e que a professora não tomou por orientação bases teóricas como as apresentadas nesta análise. Como resultado, podemos dizer que a produção textual, no que diz respeito à coesão e à coerência, poderia ter sido mais bem explorada, principalmente no retorno que os alunos devem ter após a correção da professora.

\section{CONCLUSÃO}

Cientes da importância das atividades de produção textual para o desenvolvimento da plena proficiência da língua escrita, tomamos como objeto de análise deste artigo as intervenções docentes feitas nas redações de quatro alunos da primeira série do Ensino Médio. Duas redações foram corrigidas pela Professora 1; as outras duas, pela Professora 2.

Independentemente dos temas propostos para as redações, diferentes entre as professoras, o que pudemos observar foi uma dessemelhança também na abordagem utilizada por cada uma delas nas correções.

Enquanto a Professora 1 preocupou-se com problemas relacionados ao desenvolvimento do texto, ao sentido apreensível no todo, embora comentando os pontos falhos de maneira não muito precisa (com comentários finais e breves, não-ancorados no texto), a Professora 2 deteve-se em questões gramaticais, atenta basicamente a erros de acentuação, grafia etc. Entre elas, portanto, foi a Professora 1 a que mais se aproximou das teorias sobre textualização, coesão e coerência que pautaram nossa análise e serviram às nossas críticas, mesmo sem que ela tivesse, aparentemente, o conhecimento teórico em questão e a consciência da proficuidade de colocá-lo em prática. Como seu oposto, a Professora 2 estaria próxima da pedagogia tradicional do ensino do Português, já tão criticada e, felizmente, em muito superada, que prega a rigidez no uso das normas gramaticais sem levar em conta que, muitas vezes, a forma perfeita e gramaticalmente "correta" também pode comportar o esvaziamento do sentido e, principalmente, do raciocínio crítico sobre o texto, comprometendo a leitura e a escrita dos alunos.

Além disso, ressaltamos que muitos foram os "problemas" encontrados, tanto nas redações dos alunos quanto nas correções das professoras, e o que realizamos neste estudo foi uma tentativa de identificar as possíveis bases teóricas que orientariam o processo de intervenção docente, por meio de alguns exemplos pontuais, que bem serviram ao nosso propósito.

Finalmente, quanto às referências que utilizamos como suporte, confirmamos que as teorias sobre coesão e coerência, orientando o processo de construção textual e, no caso de professores, também o processo de correção e revisão, são, efetivamente, "ferramentas" excelentes e muito podem contribuir com os profissionais do ensino do Português e do estudo da língua. 


\section{REFERÊNCIAS}

CHAROLLES, Michel. Introdução aos problemas da coerência dos textos. In: GALVES, Charlote; ORLANDI, Eni Pulcinelli; OTONI, Paulo (orgs.). O texto: leitura e escrita. Campinas/SP: Pontes, 1997, p. 39-90.

KOCH, Ingedore V. Introdução à Linguística Textual. São Paulo: Martins Fontes, 2004.

A coesão textual. 11 ed. São Paulo: Contexto, 1999.

SANTOS, Mauro Bittencourt. Contrato de cooperação e implicaturas. In: MEURER, José Luiz; MOTTA-ROTH, Desirée (Orgs.). Parâmetros de textualização. Florianópolis: Editora da UFSM, 1997. 
ANEXO 1

\section{Frente}

$1 *$

6)

Lutero

to te

Now

Rosis quose ser ationde or um rovo, Lutero pcred bu ter recebido um chomodo, edecaliu tomor se monge

Dwarle seu eshob, sempie Ie perguntova "Covbo poderia gonhar o cmor ea perdo co Deus

$$
\text { A grejo cb eqoo piegons que }
$$

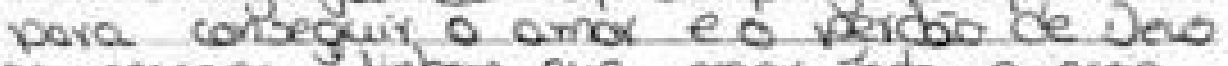
os pessoos winhom que pyop hat a igiga

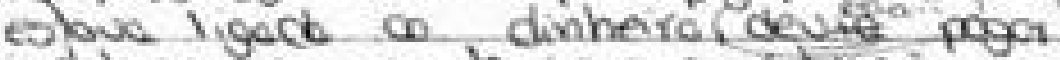
indugencsos onia buscor o solusicas, poro solver suos dinas do purgotino

Lutero for descobind do bngo de sew shubs que pova Genhor o cuds de Deus

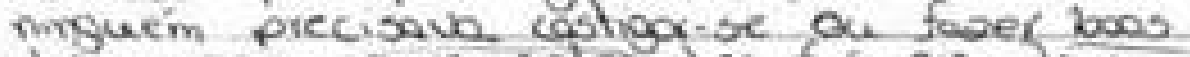

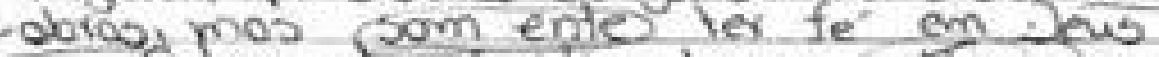
Enioo elé daudiu torner putícos ours

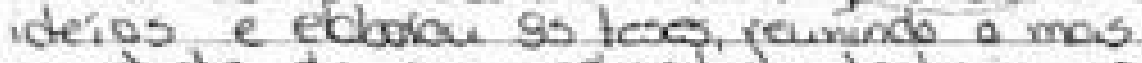
montante de suo redescobita teabigien e os preso no prita de igrigo.

C Oowigat a se rodmir publicomente, se recuso a neger os bew exiltos alc que Ia igreg catalica consig provor que suco. coloras comindism a bolia Cle pretendia abr um debte poro wo oulocos inteina de Igigo, pora que tose ienagh a potir do Euongetro de Sabus Giob Condo e picio excomingost. wes the foy 
Verso

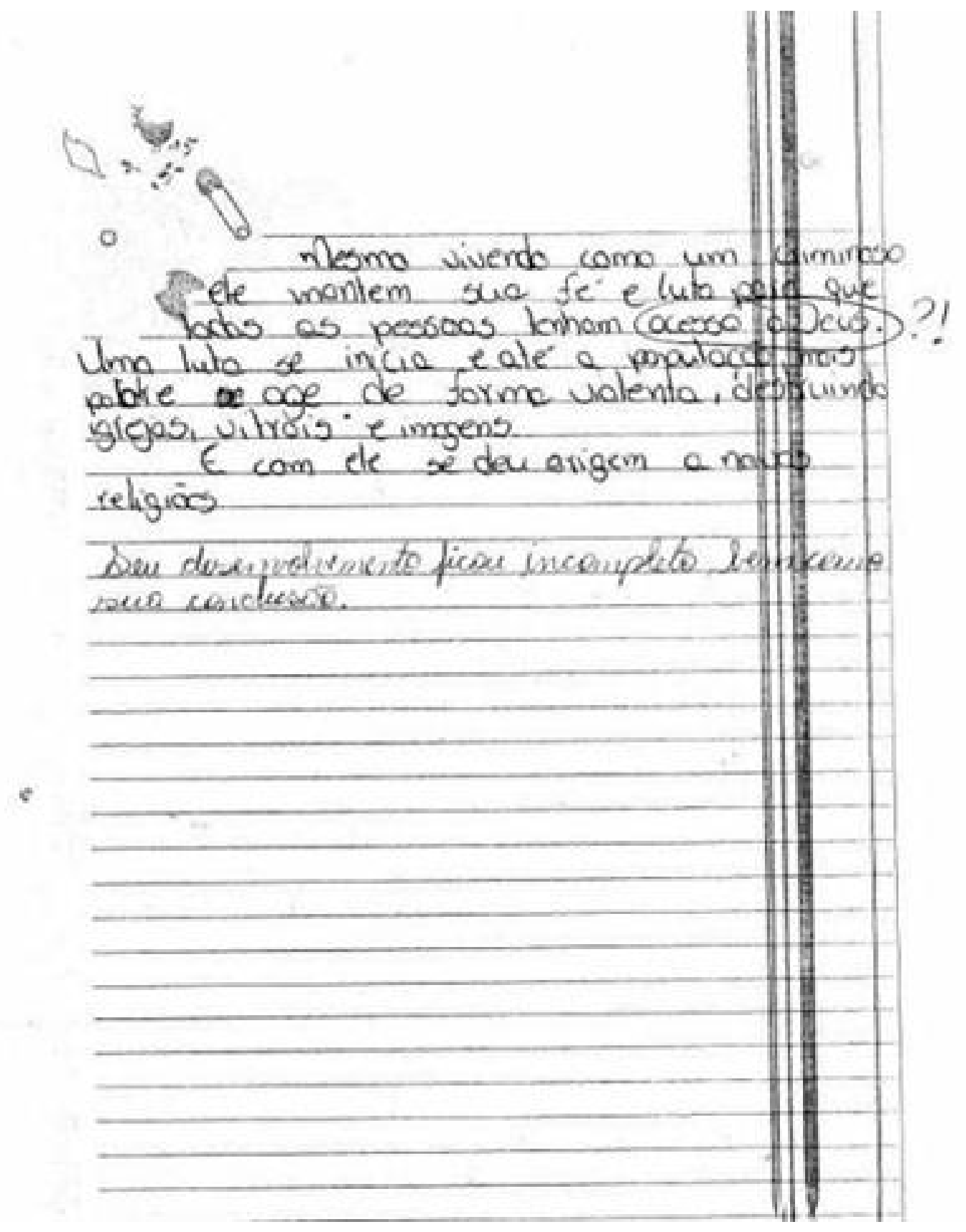


ANEXO 2

\section{Frente}

\section{Aluria:}

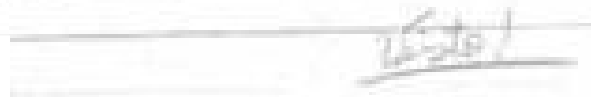
Soutions

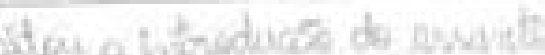

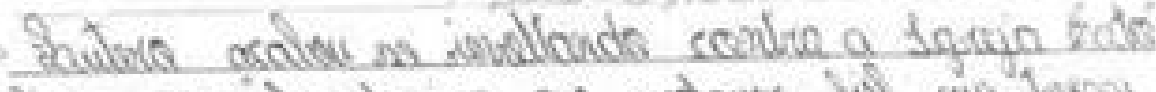

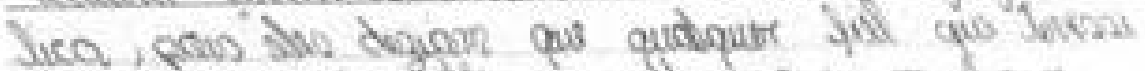

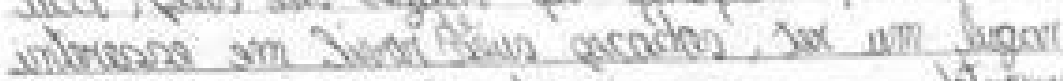

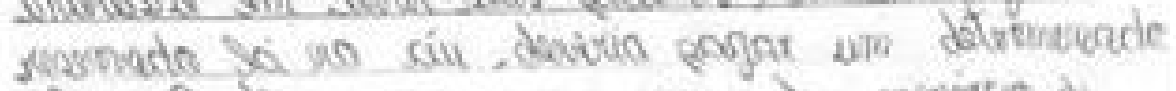

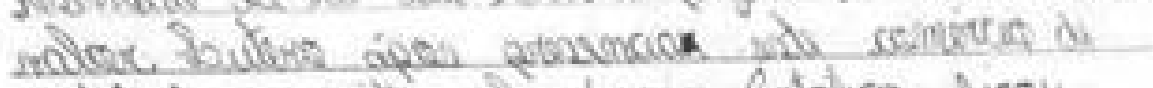

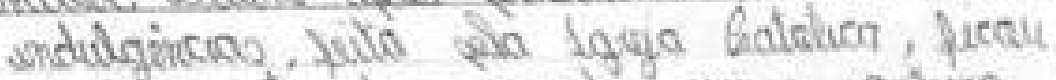

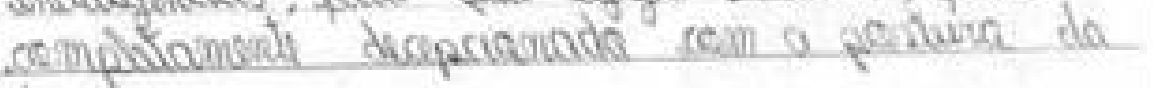
Ixien.

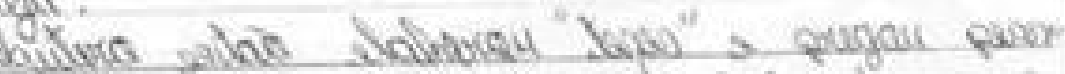

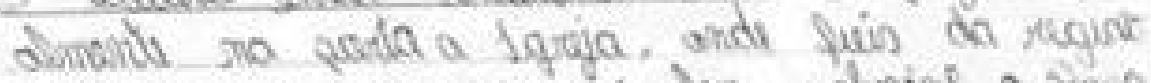

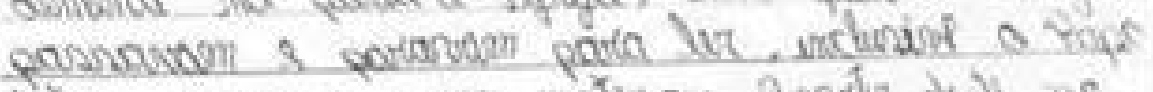

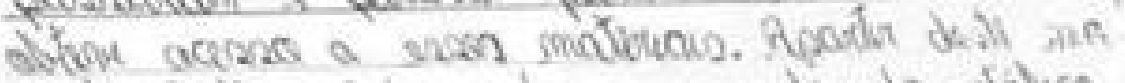

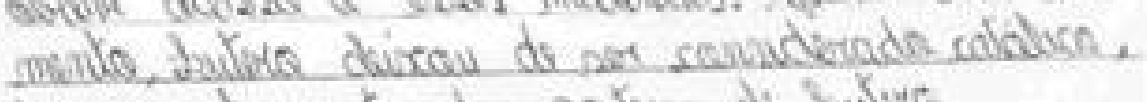

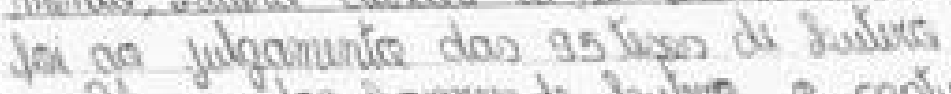
Alquo des yomaro de bulyes a capiviarin

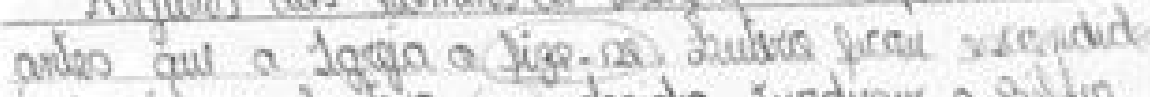
Yai ai qu butera (no deadia kradugur a buka para a lingua Almó, so no suswamo pectiv

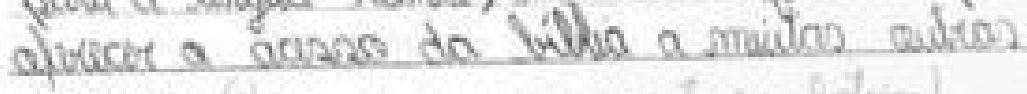

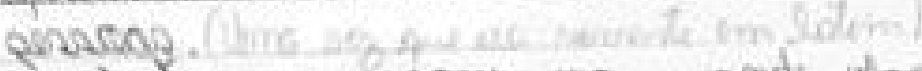

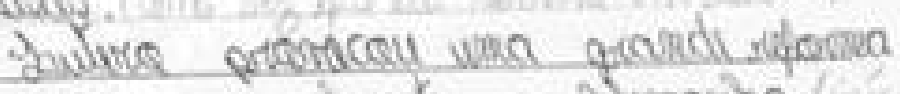

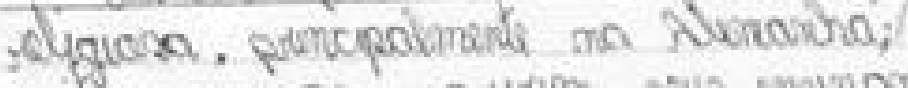

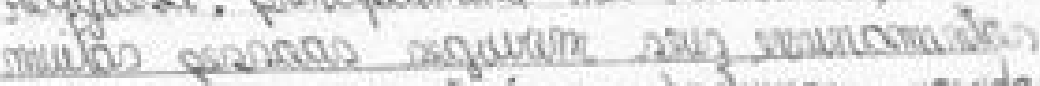
s deirearim pera tras as dautrinas nuguedas 


\section{Verso}

ala Jgueja batakica. Maunbram mutos cenprontos. Sarega apres as confrantos algumas previas fugiram, sendo uma dalas a Kalhowine, que se cosceu arm fouters, twertam 6 pithos, es lideres catelices deram a total apera em negander $n$ a condenar feutura som a iveregs

seutera marken in 1546 ,ass 63 anas, ápos ser corsamenta cunda piegeu seus enmeramentos por mans 16 anos, os efutes do prateda de

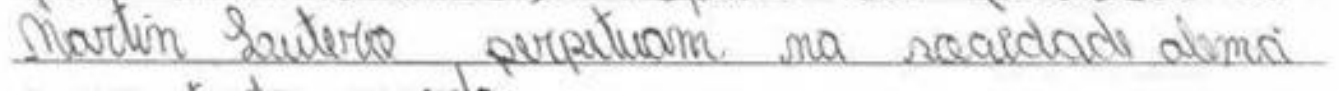
sem tode munda.

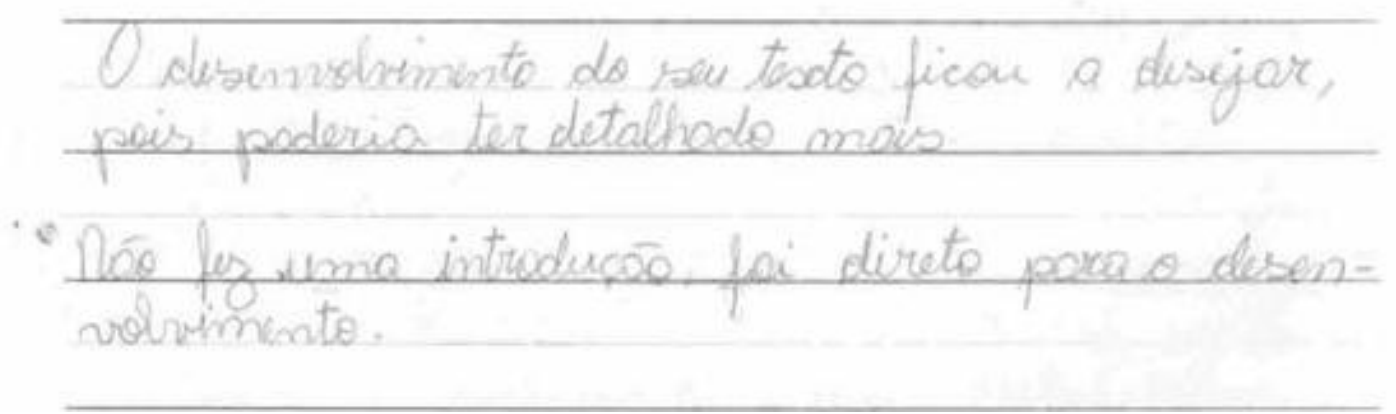


ANEXO 3

sulo.

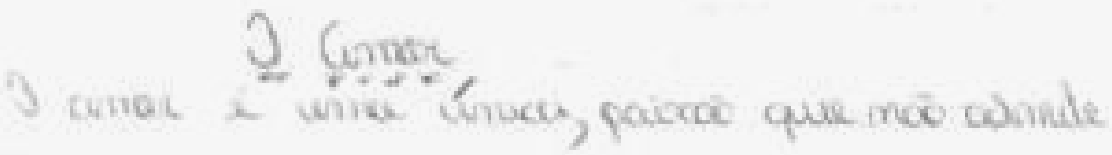

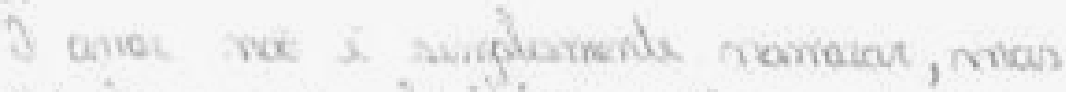

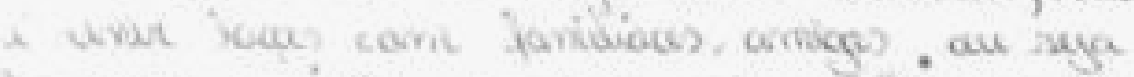

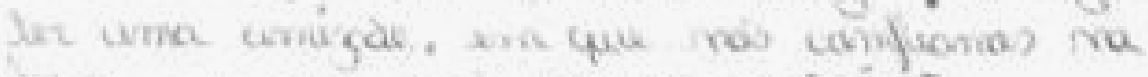

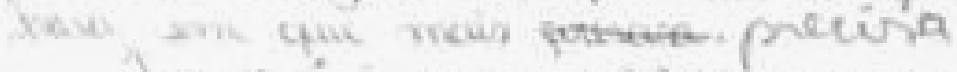

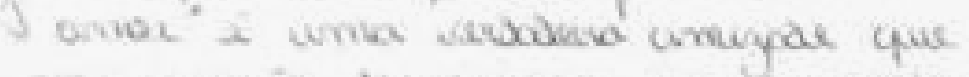

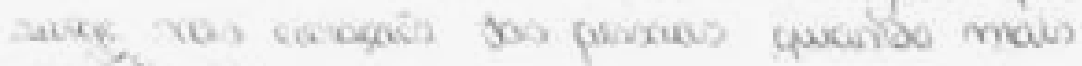

nucosibinan

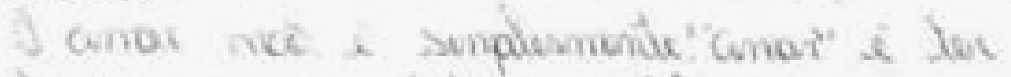

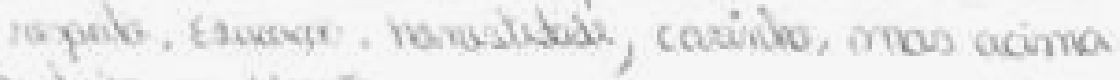

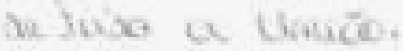

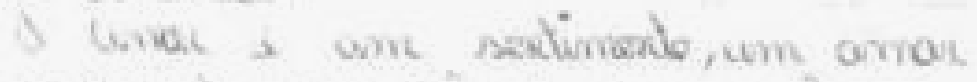

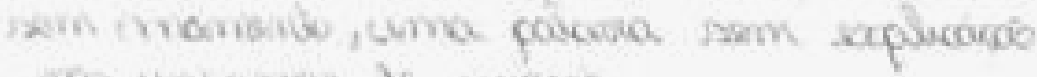

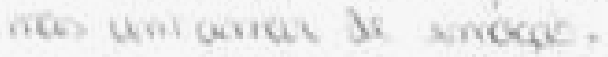

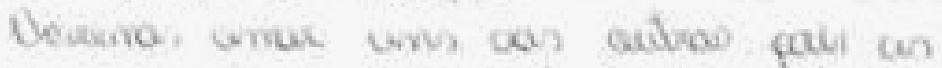

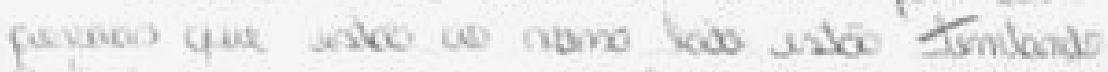

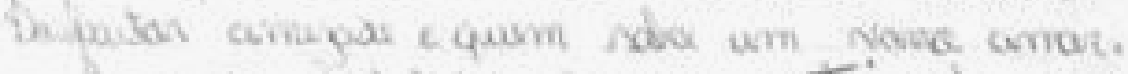

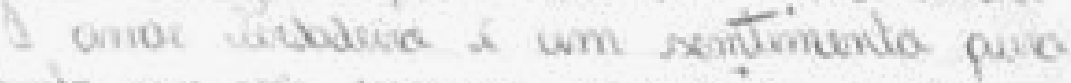

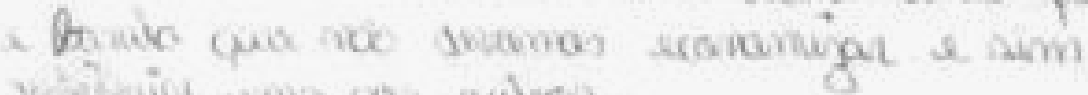
sublenist sms cos cudies.

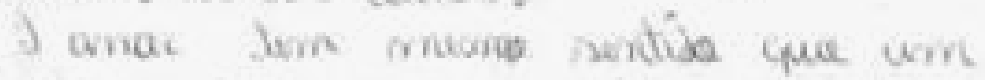

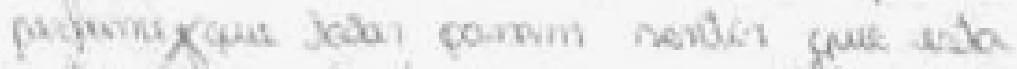

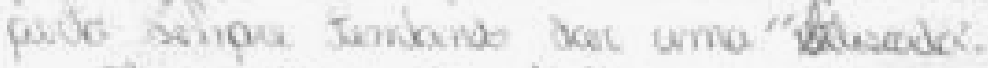

Mas cossar de tudo ino devemos

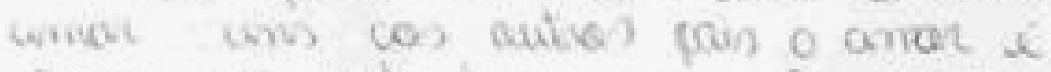

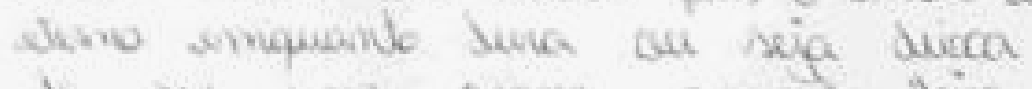

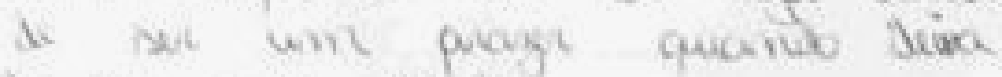
de sul wris sogulde. 


\section{ANEXO 4}

\section{Frente}

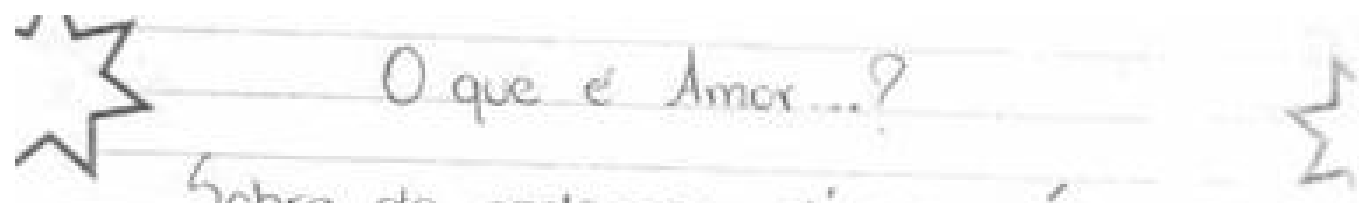

Sobre ete podemos dizer vários

7 sinônimos, mas ele é principalmente wr. plicidade, respeito e acertascio. E accitar ao outro como ele $e^{\prime}$, $\mathrm{com}$ sevs defertos e suas falhas; 0 amor e incondicional.

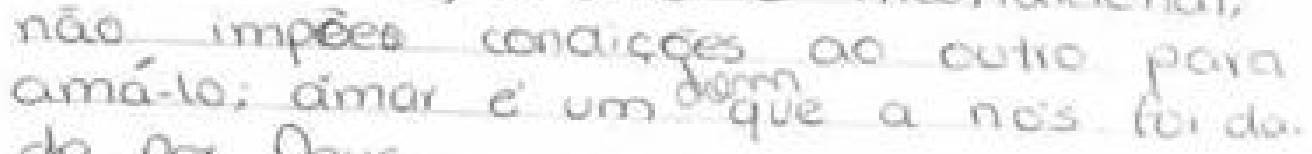
do por Deus.

Cada un tém sua forma de expre ssar o amor que sente, algums mas abertamente, outros nem tanto, algums cuidam do pessoa amada como se fosse uma joia rāra, outros aperias amam; mas, todos amam, näo importando a raca a cor.

1) amor verdadero é o sentirimento - mais puro e bonito, deve ser dado sen economizar nas doseses? pois quanto mas (2) to menos voce o manifesta moins - vocé o afosta de ti; o amor poor Wudar radicalmente a vida de uma pessoa, pode tornálla uma Dpessoa melhor, seja ele o amor \{ 


\section{Verso}

> de pai para filho, de irmacs/ 2

I de amigos, de namorados. ou acima de todos os amores o de Deus paro com as seus filhos. 